\title{
Tosinas
}

\section{Violencia y política}

Contraposición, entrecruzamiento o articulación

Lucía Vinuesa

Licenciada en Ciencia Política

(Universidad Nacional de Rosario)

Correo: luciavinuesa@gmail.com 
Resumen

El presente artículo tiene por objetivo exponer de manera resumida la tesina de grado para la obtención de la Licenciatura en Ciencia Política en la UNR. En la misma nos hemos propuesto dilucidar los modos disímiles de abordar la violencia y la política, con el objeto de señalar las características que asume una determinada noción de orden político. Como vemos, la relación entre ambas categorías y el orden resulta sustancial. Afirmar que la experiencia de lo político es la de una violencia originaria, que determina y confluye en la constitución del orden y que, en efecto, éste reproduce relaciones de dominación, implica asumir una postura determinada - nosotros diremos también: necesariafrente a corrientes de pensamiento que parecen desconocer el hecho fundamental de que la dominación sigue apelando a formas de sometimiento opresivas y coercitivas.

Palabras clave

Violencia - Política - Orden

- Filosofía política
Abstract

This article aims to expose the thesis for obtaining a Bachelor's Degree in Political Science. We intend to elucidate the dissimilar ways of dealing with violence and politics, in order to point out the features that caracterize a certain notion of political order. As we see it, the relationship between these two categories and order is substantial. To claim that the experience of politics is that of an original violence, which determines and is within the constitution of the order and reproduces relations of domination, implies taking a certain position in relation to theoretical frameworks that seem to ignore the fundamental fact that domination is still utilizing forms of oppressive and coercive subjugation.

Keywords

Violence - Politics - Order - Political philosophy 


\title{
Violencia y política. Contraposición, entrecruzamiento o articulación
}

\author{
"En la historia real el gran papel lo desempeñan, \\ como es sabido, la conquista, el sojuzgamiento, \\ el homicidio motivado por el robo: en una palabra, la \\ violencia”. \\ Karl Marx
}

El presente artículo tiene por objetivo exponer de manera resumida la tesina de grado ${ }^{1}$ para la obtención de la Licenciatura en Ciencia Política de la UNR. En la misma nos hemos propuesto dilucidar los modos disímiles de abordar la violencia y la política, con el objeto de señalar las características que asume una determinada noción de orden político, para lo cual recurrimos a dos modalidades de pensamiento de la política que nos presentan respuestas alternativas de los efectos del vínculo entre ambas categorías en la configuración del orden político ${ }^{2}$.

A partir de nuestro recorrido, observamos que la relación entre ambas categorías y el orden resulta sustancial. Afirmar que la experiencia de lo político es la de una violencia originaria, que determina y confluye en la constitución del orden y que, en efecto, éste reproduce relaciones de dominación, implica asumir una postura determinada — nosotros diremos también: necesaria — frente a corrientes de pensamiento que parecen desconocer el hecho fundamental de que

1 Realizada bajo la dirección del Dr. José Gabriel Giavedoni.

2 En este punto resulta pertinente aclarar que en la tesina propusimos como eje analítico abordar la violencia y la política a partir de un marco metodológico que contenía a la filosofía política como punto de partida y a perspectivas que analizan la política desde otros enfoques, particularmente en lo que hace al modo de entender el orden. SI bien decidimos dejar de lado en este artículo esta línea de investigación, lo mencionamos resumidamente en esta nota al pie. En efecto, al analizar esta tematización de la violencia y su correlato en el orden político, reivindicamos como necesario hacerlo en la encrucijada entre la filosofía política y la política de la tragedia. En consecuencia, valoramos positivamente los beneficios de concebir conjunta y complementariamente al pensamiento filosófico político y al pensamiento trágico. Tal como argumentamos en la tesina, ninguna de dichas formas de pensamiento de la política agota en sí misma las posibilidades de la teoría política de la violencia que nos ofrecen los autores que hemos recogido. 
la dominación sigue apelando a formas de sometimiento opresivas y coercitivas.

En este sentido, decidimos recurrir a la tradición de discurso político, hacer hablar a los pensadores modernos y contemporáneos de la teoría política, ejercicio hermenéutico de revisión bibliográfica de un valor inmenso a los fines de entrever la relación estrecha entre el orden político y los requerimientos (o no) de la violencia, en la reproducción de las relaciones de dominación. Tal como veremos, escogimos una selección $\operatorname{acotada}^{3}$ de autores clásicos que tienen mucho que decir respecto al tema de estudio, algunos pueden agruparse en los márgenes de un realismo crítico (Grüner, 2007), otros pueden ser clasificados como pensadores de lo impolítico (Espósito, 2009), así como de la tragedia (Rinesi, 2003), encontraremos también claros exponentes de la filosofía política (Wolin, 2001).

Diremos junto a Atilio Borón, de lo que se trata es de "interpelar a una «tradición viva» y no de adentrarse en un cementerio de ideas, o de internarse en el oscuro laberinto donde yacen los restos arqueológicos de la historia del pensamiento político" (1999:2). Hablamos de interpretación porque pretendimos que estos textos venerables recuperen su voz y vuelvan a hablar. Necesitamos de esas voces en estos tiempos, ya que arrasados como estamos por la amalgama de neoliberalismo y el neo-institucionalismo en la ciencia política, estamos hambrientos de buenas ideas y nobles utopías.

3 Selección cuyas ausencias resultan difícilmente excusables. En este sentido, Friedrich Engels y Antonio Gramsci, por el lado del marxismo, son aportes de un valor inmenso al problema de la violencia y la política, lo mismo ocurre con el propio Lenin. Por otro lado, una lectura de George Sorel hubiese sido interesante, y un largo y culposo etcétera. Como ocurre siempre que emprendemos una investigación, el tiempo es tirano con nosotros, sometiéndonos a la ineludible obligación de recortar — sin asco- nuestros márgenes de estudio. 


\section{Teoría de la violencia y de la acción política en el marco de un orden político signado por el conflicto y la imprevisibilidad}

En el primer capítulo, nos propusimos un recorrido por algunos textos de Maquiavelo representativos del modo en que concibe la relación entre el orden político y la violencia en tanto categoría política. Como veremos, el autor se perfila como el padre de la Nueva Ciencia Política, con una concepción realista de la política, destierra de la misma la idea de un bien superior. Por otro lado, el orden político es un círculo cerrado que tiene en sí mismo su fundamento, al mismo tiempo que una totalidad sobrevenida gracias a una violencia fundadora y conservadora.

Maquiavelo tiene el mérito de concebir una teoría de la violencia que responde a los requerimientos de una política que se presenta inestable, siempre en vilo frente a los avatares de la Fortuna, y mediada por la presencia de múltiples y disímiles intereses contrapuestos. En un contexto como el descrito, el autor ofrece una teoría de la violencia, de su aplicación juiciosa, en este camino, se perfila como un teórico político de la acción, en tanto vislumbra que el actor político debía acomodar su temperamento y elegir determinadas vías de acción de acuerdo con las demandas de la coyuntura y sus circunstancias cambiantes ${ }^{4}$.

Todo el pensamiento maquiaveliano está atravesado por su preocupación frente a la desorganización política de la Italia renacentista y por la inestabilidad de la República florentina. La nueva ciencia política intenta hacer inteligibles los fenómenos políticos en momentos en que los ordenamientos sociales y políticos tradicionales parecen disolverse. Motivado por el impulso de aconsejar al actor político acerca de cómo conformar y conservar el gobierno, Maquiavelo no puede menos que depositar esperanzas inmensas en el accionar de

4 En este punto, debemos aclarar que nuestra lectura de Maquiavelo se encuentra fuertemente condicionada por el tratamiento que el autor brinda a la política y la violencia en El Príncipe. De este modo, tal como se desprende de dicho texto, el sujeto político juega un rol prioritario en las apreciaciones del florentino sobre las instituciones políticas. A diferencia de lo que ocurre en los Discursos sobre la primera década de Tito Livio. 
dicho sujeto, es decir, el príncipe nuevo. En este camino, reconoce el carácter ineludiblemente violento de la política, el orden efectivamente se funda y conserva sobre medios violentos, el bien tiene lugar solo a partir de un mal fundador.

En el marco analítico que nos brinda la filosofía política, y algunas visiones contrapuestas, veremos los rasgos peculiares que nos permiten pensar la teoría política de la violencia en Maquiavelo como aquella que aparece como necesaria para los requerimientos de la instauración y mantenimiento del orden político, sin lograr emanciparse totalmente de los avatares trágicos de la fortuna (Rinesi, 2003).

\section{Orden político, violencia y teoría de la acción política}

El mal, el temor y la violencia adquieren un rol protagónico en la conformación de un Estado para hacerlo durable, Maquiavelo lo reconoce con precisión. De este modo se permite valorar los homicidios de Rómulo en los orígenes de Roma. En el libro noveno de los Discursos (Maquiavelo, 1996) refiere a la historia de dicha ciudad italiana, particularmente a su nacimiento, es decir, a Rómulo, quien fue el instaurador del orden civil. A partir de esta historia, Maquiavelo reconoce dos violencias, la que compone y la que estropea (Manent, 1990).

En este sentido, desde la perspectiva de Maquiavelo, Rómulo, a pesar de asesinar a su hermano y a su compañero, tenía por fin trascendental el bien común. El florentino dirá que aunque "(a Rómulo) le acusan los hechos, le excusan los resultados, cuando éstos sean buenos, como lo fue con Rómulo, siempre le excusarán, porque se debe reprender al que es violento para estropear, no al que lo es para componer" (1996:57).

Estas violencias pueden pensarse a partir de su carácter de legitimidad, si el fin es la constitución de la ciudad como un orden político que debe construirse, protegerse y sostenerse a lo largo del tiempo. Necesariamente Maquiavelo debe señalar esta distinción si aspira a perfilar un Estado duradero. El ejercicio de la violencia no es negativo o pernicioso para los fines del principado o del Estado, incluso puede resultar eficiente (e ineludible) en el mantenimiento del orden, un 
asunto que Maquiavelo no logra resolver del todo, como veremos, es el modo en que la Fortuna puede escapar del control del gobernante, incluso, y a pesar, del empleo de la fuerza.

Ahora bien, podemos volver sobre Manent (1990) en vistas a repasar sus argumentos acerca de la fecundidad del mal en el orden político a partir de su propia lectura de los textos de Maquiavelo. De este modo, en base al carácter sustancial del mal en la vida política, la ciudad viene a ser una isla artificial construida por medios violentos. Resulta absurdo querer mejorar el bien de la ciudad gracias a un bien superior que aportaría la religión - como bien han propuesto los escolásticos-, ya que dicho aporte no haría más que desbaratar el funcionamiento natural de la ciudad. Resulta entonces que al afirmar la necesidad y fecundidad del mal se está aseverando la autosuficiencia del orden terrestre, del orden profano. El cuerpo político es, sin dudas, una totalidad cerrada y sobrevenida gracias a la violencia fundadora y conservadora (1990:43-46).

Por su parte, Cassirer (1947) hace referencia a la fascinación de Maquiavelo por César Borgia y sus métodos para deshacerse de sus enemigos, los cuales no se entienden si pensamos como fuente de admiración al hombre mismo (Borgia), sino la estructura del nuevo estado que él había creado. En este sentido, "Maquiavelo fue el primer pensador que se percató completamente de lo que significaba en verdad esta nueva estructura política" (1947:160). El análisis de Cassirer viene a reforzar nuestra concepción del mismo Maquiavelo y su aporte a la tesina presente. Con Maquiavelo la distinción entre moral y política asume un carácter explícito, a su vez, el temor y la violencia se reconocen como medios no solo válidos sino necesarios y deseables cuando así lo demanden las circunstancias. Por otro lado, afirmamos que Maquiavelo desestima la existencia de un bien superior que trascienda la ciudad y que la misma está construida por y sobre medios violentos.

En estos términos, podemos extraer una determinada concepción del orden político que se funda y mantiene sobre el empleo de la violencia en manos del gobernante. A lo cual debemos agregar otros elementos ineludibles como la búsqueda de legitimidad en las masas 
por parte del príncipe o actor político. Desde la perspectiva que nos ofrece Maquiavelo, resulta de una importancia sustancial el obtener la aprobación del pueblo, como forma de legitimación. El recurso a la violencia y el temor son aconsejables, pero al mismo tiempo, el autor esboza una apreciación de las masas que lo sitúa a distancia del cristianismo y del pensamiento griego. Estas características nos permiten pensar a Maquiavelo como un fiel representante de la Nueva Ciencia Política, veamos cómo se perfila la misma a partir de una determinada concepción del orden político.

El mundo de la política se encontraba vibrante de cambio, se vislumbra en Maquiavelo un alejamiento de las cuestiones en torno de la autoridad legítima, con sus connotaciones de un mundo político estable, para acercarse a cuestiones de poder o de la capacidad de ejercer el dominio mediante el control de un complejo inestable de fuerzas en movimiento. Ya no era tan sencillo establecer distinciones sutiles en base a la fugacidad de los acontecimientos. Es posible afirmar junto a Wolin que la gran innovación maquiavélica consiste en la insistencia de la realidad del movimiento y el cambio, este es el principio unificador básico (2001:232).

\section{La economía de la violencia y la}

\section{teoría de la acción política}

A continuación, proponemos un abordaje conjunto de la idea de acción política en Maquiavelo y de la economía de la violencia porque consideramos que no es posible pensarlas como términos estancos. Más bien, un análisis que implique ambas teorías puede resultar esclarecedor del modo en que Maquiavelo postula su teoría del orden político como uno inestable, cambiante, y cuyas disímiles circunstancias coyunturales obligan al sujeto político a adoptar uno u otro temperamento, así como aplicar o no la fuerza. Como hemos visto, la teoría de la acción estaba emparentada a la virtù del actor político, a su capacidad de torcer la Fortuna cuando esta se presente desfavorable. Por eso la misma - la virtù - está siempre determinada por una coyuntura, debe ejercerse siempre en una cierta situación de hecho. Esa coyuntura ofrece al actor político la materia sobre la cual su virtì 
debe practicarse, pero esa "materia" no es una arcilla blanda y dócil, ella misma dicta el método con el cual puede ser trabajada, determina en cada situación concreta qué es lo que debe ser considerado una conducta virtuosa (Rinesi, 2003:52).

La política adquiere el perfil de un arte incierto y temerario. No hay reglas ni leyes de acción que pueden aplicarse universalmente. De todas maneras, Maquiavelo aconseja que el actor político se guíe como norma general de acción —en este mundo incierto y cambiante- el ser atrevido antes que circunspecto. En este marco, y en camino de guiar al príncipe nuevo, Maquiavelo no podía efectuar contribución mayor que crear una economía de la violencia. Es decir, una ciencia de la aplicación controlada de la fuerza (Wolin, 2001:239). Como tal, tendría por tarea la de proteger el límite que separaba la creatividad política de la destrucción. "El control de la violencia dependía de que la nueva ciencia pudiera administrar la dosis precisa adecuada para situaciones específicas" (Wolin, 2001)

Es importante entender que Maquiavelo no consideraba a la economía de violencia como un medio para reducir la magnitud del sufrimiento en la condición política. Al mismo tiempo, podemos decir que esperaba promover mediante su economía de la violencia "el empleo "puro» del poder, no mancillado por el orgullo, la ambición ni motivos de mezquina venganza" (Wolin, 2001:241). Es decir, el Estado a partir de Maquiavelo es directamente encarado como una suma de poder, cuyo perfil era el de la violencia. Efectivamente, "opinaba que los elementos vitales de la actividad política no podían ser controlados ni orientados sin aplicar la fuerza y al menos la amenaza de violencia" (Wolin, 2001:238).

De todas maneras, resulta interesante recordar que, a nivel interno, Maquiavelo creía posible estructurar la política de una sociedad mediante métodos encaminados a minimizar la necesidad de actos de represión extremos. En este sentido, "la importancia de la ley, las instituciones políticas y los hábitos de civilidad residía en que, al regularizar la conducta humana, ayudaban a reducir la cantidad de casos en que se debía aplicar la fuerza y el temor" (Wolin, 2001:240). 
Interesa destacar del constructo teórico maquiaveliano los elementos que nos permiten vislumbrar características propias del Estado moderno tal como lo conocemos. En este sentido, el temor y la violencia pueden ser emparentados con un modelo de Estado entendido en términos gramscianos (Althusser, 1997; 2004). Especialmente si tenemos en cuenta que el temor no se presenta sólo como el sentimiento del pueblo hacia el principio, sino también de éste hacia el pueblo y en este camino se orienta su necesidad de legitimarse entre las masas. La búsqueda de consentimiento entre el pueblo, si bien parece desvalorizada por momentos, es una preocupación presente en el autor florentino. A esta altura, resulta imprescindible ser conscientes de que la meta principal de Maquiavelo es perfilar un modo de gobierno que le permitiera al príncipe conservar el poder. En este camino, el príncipe debía ser capaz de variar su conducta, de buena a mala y viceversa "según lo dicten la fortuna y las circunstancias" (Skinner, 1993:163). Al mismo tiempo, debe conseguir ser temido, pero no odiado. La violencia que aparece en los orígenes debe saber utilizarse cuando lo demanden las circunstancias.

\section{La violencia y sus formas diferenciales según su naturaleza. Procesos de monopolización de la violencia órdenes políticos centralizados}

En el capítulo segundo hemos reagrupado a algunos autores que, a pesar de sus diferencias sustanciales, pueden ubicarse en una misma línea de pensamiento político realista. En este sentido, diremos que confluyen en una conceptualización de la violencia y la política, concibiéndolas a partir de procesos de monopolización de la violencia y de su organización en una estructura centralizada de poder. Estas unidades logran hegemonizar la violencia legítima, los hombres ya no temen a la muerte en manos de otro hombre, el miedo se reconfigura, se internaliza y actúa como contención de las emociones e impulsos, al mismo tiempo que se dirige al Estado, es decir, el temor de los hombres a ser castigados. 


\section{Introducción al pensamiento científico}

\section{y político hobbesiano}

Como veremos, Thomas Hobbes configura la noción de orden político a partir del modelo de Estado que refleja el Leviatán. El estado de naturaleza aparece como el dispositivo teórico que nos permite comprender las características de un orden pre-político, en el cual la violencia es horizontal, anárquica, impredecible y el temor frente a la muerte violenta es una constante entre los hombres. El Leviatán se erige frente a este des-orden y aglutina en sus manos el ejercicio de la fuerza sobre los súbditos. La violencia se torna predecible, se ejerce vertical y legítimamente. Con relación a las condiciones subjetivas que llevan a la lucha natural entre los individuos en el estado de naturaleza, el autor detalla tres específicamente que, aun si fuera pertinente mencionarlas, resumiremos en una sola: la de una innata inclinación del género humano al deseo de poder, un deseo constitutivo que sólo puede ser eliminado por la muerte. Pues bien, si centramos nuestra atención en este deseo, podemos apreciar que tiene que ver con la característica antropológica fundamental que, según Hobbes, determina la finalidad esencial del ser humano; es decir, conservar su propia vida dirigiéndose hacia lo que la hace posible (el bien) y huyendo de lo que la pone en peligro (el mal). El deseo de poder es, por tanto, el impulso natural que empuja el ser humano hacia la satisfacción forzosa de esta necesidad primaria y elemental: la autoconservación vital.

Ahora bien, una vez que comprendemos que el deseo de poder y el de la autoconservación vital inclinan a los hombres a estar alertas unos a otros y, en algunos casos, a luchar entre ellos, nos preguntamos si esos elementos se encuentran presentes en todo momento y lugar, y acerca del carácter mismo del peligro - y temor- a la muerte violenta. Es posible comenzar afirmando que ese peligro de muerte violenta se extiende a todos y es, además, permanente. De hecho, aun cuando no se encuentren efectivamente en guerra, en el estado de naturaleza, los individuos viven bajo la amenaza constante del conflicto, pues el conflicto está siempre presente como disposición 
natural, tal y como muestra la ilustrativa metáfora climatológica a la que recurre Hobbes en estas páginas.

\section{El estado de naturaleza como aquel característico del vacío político}

De modo que, lejos de representar el momento originario de toda comunidad posible, Hobbes concibe el estado de naturaleza más bien como el riesgo que corre toda comunidad política si su poder soberano no está debidamente fundamentado. En este sentido, se trata del riesgo que corre todo estado cuando cae al estado anterior y la mayoría de los hombres se encuentran viviendo sin orden establecido por falta de un poder común, con la desconfianza recíproca y el temor permanente a la muerte violenta que caracterizan eminentemente los conflictos civiles. De este modo, observamos que en el autor del Leviatán, la natural conflictividad humana, y con ésta la violencia y el temor a la muerte como formas extremas de manifestación de dicha fenomenología (Firenze, 2013), juegan un rol determinante para comprender el fundamento — en tanto origen y legitimidad- del orden político, y tal vez podríamos aventurar, de su reproducción.

Este estado de vacío político o su amenaza permanente, debe ser observado incluso con mayor detenimiento. Si comprendemos, junto a Wolin (2001), que el estado de naturaleza hobbesiano simbolizaba también una condición confusa por la anarquía de significados. El problema planteado en estos términos era también filosófico e implicaba la jerarquía del conocimiento. El estado de naturaleza constituía el caso clásico de subjetivismo, en este sentido, el estado de naturaleza representa la culminación de un constante aumento del desacuerdo en cuanto a los significados comunes y fundamentales, el deseo de cada uno de buscar aquello que es bueno para él. En consecuencia, Hobbes no toleraba la primacía de la razón privada porque originaba una confusión de significados que destruía el cuerpo político como un todo en comunicación.En estos términos, podemos decir que el orden político hobbesiano no hace más que anular el conflicto de intereses que Maquiavelo reconocía como propiamente político. Es posible poner en duda el carácter de "vacío político" del estado de 
naturaleza, ya que bien puede pensarse que solo en dicho estado impera el conflicto inherente a la política y la noción de comunidad, que justamente el contrato de la sociedad civil anula al priorizar el interés individual de cada sujeto al pactar.

Llegados a este punto resulta valioso reconocer al conflicto como uno de los elementos que Hobbes intenta erradicar al prefigurar su Leviatán. Por otro lado, desde ya reconocemos el rechazo hobbesiano de la sociabilidad natural como fundamento de la comunidad, lo cual constituye precisamente el primer punto de ruptura con la tradición ético-política antigua y, a su vez, el elemento teórico que inaugura la configuración moderna del pensamiento de la comunidad. Basta con recorrer las conocidas páginas del libro XIII del Leviatán acerca del estado de naturaleza para percatarse del giro radical que Hobbes imprime de manera inaugural a la filosofía política occidental determinando, hasta nuestros días, el horizonte todavía abierto de su intrínseca problematicidad.

Esa conflictividad inherente al orden social es la que preocupa a Hobbes, es también, el conflicto que deviene posible frente a la aparición de partidarios dentro del mismo Leviatán, es decir, cuando el poder soberano es disputado, cuando aparecen divisiones. En consecuencia, es posible afirmar que es justamente el carácter propiamente político, si entendemos al mismo como el espacio de disputa de sentidos, el que busca eliminar el Leviatán de Hobbes. El Leviatán se erige frente a la propia precariedad del orden.

Sin embargo, en este punto no podemos dejar escapar una cuestión. Si bien reconocemos la validez de los preceptos descriptos precedentemente, quisiéramos destacar la cuestión del conflicto, de su estado siempre latente, incluso en tiempos de paz. Desde una mirada complementaria a la que venimos rescatando, puede pensarse todo el aparato teórico acerca del estado de naturaleza como una descripción realizada por Hobbes frente al temor que le provoca la política misma. En este sentido, al instituir el Leviatán no estaría creando la 
sociedad civil y con ella, el orden político ${ }^{5}$, antes bien, creemos que de ese modo estaría anulando lo impredecible de la política misma, su carácter conflictivo irremplazable. Justamente, frente a esta empresa de desterrar el conflicto propio de las relaciones sociales, la violencia ejercida verticalmente, de modo predecible y exclusivo en manos del Leviatán, aparece como necesaria en la generación de este nuevo orden político y social. El temor, que en el estado de naturaleza aparecía a raíz del riesgo de morir en manos de otro(s) y de un modo violento, sufre una transformación y ahora se reactualiza en el Leviatán, adquiriendo la forma del miedo frente a las consecuencias de des-obedecer o infringir la ley, es decir, frente a la espada pública que se erige como el aspecto coercitivo del pacto civil.

\section{Max Weber, el recurso a la violencia legítima como medio específico del Estado moderno}

Por su parte, Max Weber concibe al Estado como la asociación política por excelencia y le asigna un medio específico que consiste en el monopolio de la fuerza física legítima sobre un territorio delimitado. El proceso que conlleva a esta monopolización de la violencia y a la conformación del Estado moderno, coincide con el desarrollo capitalista, en base a esta simultaneidad y mutua implicancia, el Estado adquiere las mismas características que la empresa capitalista. En relación con la noción de la violencia, el Estado aparece como el organizador, aglutinador de un conjunto de violencias disímiles que preexisten al mismo, al hablar de monopolio reconoce la existencia de fuerzas en disputa, por eso, el Estado se tornaría hegemónico en el ejercicio de la violencia, la suya es efectivamente legítima a diferencia de las otras.

La asociación política como tal puede ser definida sociológicamente a partir de su actividad, sin embargo, Weber arguye que dicha tarea resulta muy difícil ya que históricamente las mismas han ido

5 De hecho, Soares, quien es citado por Rinesi (2003), nos induce a pensar el pacto como un artificio de la razón para generar el orden político, no porque lo instituya, sino porque colabora, en cuanto idea determinante de actitudes propias a súbditos reverentes, con su preservación o reproducción. Es decir, el orden político que instituye el Leviatán es uno de sumisión, pero no es una creación ex nibilo. 
cambiando, no hay ninguna que pueda decirse que sea competencia exclusiva de estas que hoy llamamos Estados. En base a dicho reconocimiento, nos informa que el mismo solo puede ser definido por un medio específico que él, como toda asociación política, posee: la violencia física. Luego aclara que la violencia no es, naturalmente, ni el medio normal ni el único medio de que el estado se vale, pero sí es su medio específico, este dato es fundamental. Weber encuentra en la actualidad, una relación especialmente estrecha entre el estado con la violencia, a diferencia del pasado, cuando las más diversas asociaciones, comenzando por la asociación familiar, han utilizado la violencia como un medio enteramente normal.

\section{Aportes a la teoría de la monopolización de la violencia}

física en el marco del proceso civilizatorio occidental

En el caso de Norbert Elías (2009), las unidades centralizadas de poder que monopolizan el ejercicio de la violencia, solo se comprenden a partir del desenvolvimiento civilizatorio. En el mismo, resulta fundamental comprender la simultaneidad de las transformaciones de la estructura de personalidad y las estructuras sociales, gracias a las cuales los hombres asumen pautas de control de las emociones. El estudio de las estructuras sociales y de personalidad conlleva un aporte sustancial a la cuestión del monopolio de la violencia. En estos términos, el proceso de constitución del Estado, como una composición formada por muchas pequeñas unidades sociales que se encuentran en libre concurrencia, se entiende, por un lado, por la dinámica endógena de la misma composición, es decir, por su tendencia inmanente a construir un monopolio con las unidades libremente competitivas. Por el otro, en base a la auto-vigilancia, el autocontrol, el dominio de las emociones espontáneas que se produce al mismo tiempo que la monopolización de la violencia física y la ampliación de las secuencias de acción y de las interdependencias en el ámbito social.

El aporte de Elías (2009) resulta clave para pensar procesos de des-conflictualización, diferenciación e integración de grupos sociales, en vistas a comprender la conformación de espacios pacificados a partir de la monopolización de la violencia física en órdenes centra- 
lizados. A lo largo de esta obra, Norbert Elías, intentará un recorrido, a partir de observaciones, del modo en que los hombres asumen pautas de control de las emociones. Su estudio trata de procesos de larga duración de las estructuras sociales, así como las estructuras de personalidad. Concebimos importante recuperar esta lectura en tanto marco analítico para advertir los procesos de modelación social en el sentido de la civilización occidental, modelación posible a partir de una auto-coacción de los hombres, en este sentido se entiende la importancia de estudiar simultáneamente las estructuras de personalidad y las estructuras sociales. Específicamente, vamos a destacar el proceso de monopolización de la violencia, la conformación de espacios pacificados.

La auto-vigilancia, el autocontrol, así como el dominio de las emociones espontánea, la contención de los afectos, la ampliación de la reflexión más allá del estricto presente para alcanzar a la lejana cadena causal y a las consecuencias futuras, son aspectos distintos del mismo tipo de cambio del comportamiento que se produce necesariamente al mismo tiempo que la monopolización de la violencia física y la ampliación de las secuencias de acción y de las interdependencias en el ámbito social. De este modo, tiene lugar una modificación del comportamiento en el sentido de la civilización (2009:542). Al mismo tiempo, gracias a un monopolio de un poder central, la amenaza física del individuo va haciéndose cada vez más impersonal y no depende de modo tan directo de los afectos y los impulsos momentáneos, sino que progresivamente va sometiéndose a normas y leyes exactas. Finalmente, acaba suavizándose dentro de ciertos límites y con ciertas variaciones, incluso en el caso de quebrantamiento de la ley (2009).

El aspecto más interesante que nos aporta a nuestra reflexión Elías se relaciona con el modo de concebir este monopolio de la violencia física. En tanto no se presenta únicamente como una imposición centralizada y ejercida verticalmente, del modo en que podemos pensarla a partir del Leviatán hobbesiano o del Estado weberiano. Lo novedoso en el proceso civilizatorio reflejado por Elías está en este doble 
proceso de transformación de las estructuras de la personalidad, por un lado, y las estructuras sociales, por el otro.

\section{La violencia como fundadora y reproductora de un orden de dominación capitalista: Jean-Jacques Rousseau y Karl Marx}

A continuación, abordamos conjuntamente las perspectivas analíticas acerca de la violencia y el orden político que nos ofrecen Rousseau y Marx. Algunos puntos de contacto entre ambos, nos permiten vislumbrar que su principal aporte a nuestra tesina se orienta al modo en que reconocen en la sociedad civil, para el caso de Rousseau, y en el Estado, en Marx, las formas que asume el orden político de dominación moderno y capitalista a partir de la institución de la propiedad privada, o bien, del mismo desenvolvimiento dialéctico del capitalismo, instauración siempre acompañada por la violencia, amparada en la legislación misma que viene a erigir. En este entramado, las leyes, el derecho, el contrato civil o el Estado aparecen como las garantías que permiten instituir por derecho la desigualdad entre los hombres, las clases sociales. Las diferencias entre ambos son marcadas, por este motivo, dedicamos a cada uno un análisis profundo que nos permita vislumbrar en detalle la relación entre el mal, la violencia y la desigualdad entre los hombres viviendo en sociedad, y, por otra parte, la relación entre capital, trabajo y Estado que nos aporta Marx, quien no escatima esfuerzo en su descripción de la legislación opresiva que acompaño (y acompaña) la acumulación capitalista originaria (o por desposesión si consideramos que la misma está plenamente vigente).

En principio, Rousseau se erige como aquel filósofo contractualista que no puede eludir una crítica profunda a la sociedad civil, en la que predominan los crímenes, el mal entre los hombres, la violencia y la desigualdad más profunda con relación a la propiedad, todos elementos sociales que el autor reconoce como consecuencia del pacto inicuo que funda esa misma sociedad. Contrato civil que legisla y otorga derecho a la propiedad privada, generando así relaciones 
de poseídos y desposeídos, introducen la desigualdad en el centro del mundo político. Rousseau señala en el contrato social ilegítimo y perverso, que respalda la sociedad civil moderna, el desenvolvimiento violento que gesta todas las instituciones de la modernidad: la razón, la propiedad, la sociedad civil, las instituciones políticas. El mismo, como puede observarse en su denuncia ferviente, no tiene por fin fundar la legitimidad de la sociedad, la de los representantes políticos o establecer las bases justas de la convivencia social. Más bien, viene a ocultar los mezquinos intereses de las clases poderosas, es un artilugio del rico para engañar a los débiles.

Por nuestra parte, concebimos elementos de historicidad precisa en el entramado teórico rousseauniano, creemos que son justamente dichos elementos sociales como la propiedad privada, la desigualdad, la organización en clases sociales de poseídos y desposeídos, la legislación que los ampara, los que nos permiten encontrar en el ginebrino cierto perfil proto-marxista. Rousseau no describe cualquier sociedad existente, más bien, su observación se dirige a las características que presenta el contexto en que él vivió, con el capitalismo competitivo en pleno desarrollo. Esta es, a su vez, la sociedad realmente existente, donde afloran con fuerza los elementos de una sociedad capitalista, sociedad conformada por individuos, egoístas, propietarios, las guerras y la violencia.

La unión que funda el contrato civil, que reconoce y garantiza la desigual distribución de la propiedad privada, provoca los males que ella misma pretende luego corregir. En contraposición a ese orden político corrupto, inicuo, de dominación y sometimiento violento, Rousseau presenta un modelo social o pacto social superador, donde confluyan las voluntades de todos los hombres en una voluntad general que instituya el contrato social, que produzca una unión social asentada en la justicia y en la distribución equitativa de la propiedad. El "terrible esfuerzo", en términos de Espósito (2012), que lleva a cabo Rousseau para que el poder del Estado coincida con las voluntades de cada uno de los súbditos, o bien, para atribuir la soberanía al cuerpo social por entero, nos inclina a concebir al entramado teórico del ginebrino, como aquel que, si bien rechaza el orden político vi- 
gente, pretende refundarlo sobre otros elementos. Es decir, encontramos en Rousseau aspectos típicos del pensamiento filosófico político, efectivamente aprecia como posible y necesario diseñar e instituir un modelo político des-conflictualizado, un orden social reconciliado consigo mismo.

En el caso de Marx encontramos dificultades mayores a la hora de incluirlo o no en la tradición de pensamiento político filosófico, en primerísimo lugar se debe a que nuestro recorrido por su obra teórica y filosófica política es sumamente acotado. Por este motivo, descartamos el intento de "encasillar" el pensamiento de la política propio del autor en vistas a valorar y priorizar el entramado analítico que esboza Marx acerca de la violencia que acompaño el desarrollo del capitalismo en sus orígenes. Como pudimos observar, solo es posible comprender la plena instauración y desenvolvimiento histórico y geográfico capitalista, a partir del análisis de la relación entre capital, trabajo y Estado. En base a la misma, es posible entender al entramado político y jurídico que asume una forma característica en el Estado-nación moderno, como el que viabilizó las relaciones de sometimiento entre poseedores de los medios materiales de producción y los trabajadores que fueron desposeídos de las tierras comunales que trabajaban. Marx aborda un contexto histórico específico, con sus características y su legislación correspondiente, sin embargo, a partir de otras interpretaciones posibles del capítulo XXIV de El Capital, podemos afirmar que la violencia ejercida en los orígenes del capitalismo tiene absoluta actualidad, si bien asumen formas diferentes de acumulación (Harvey, 2005).

\section{Violencia y política a partir del orden jurídico que establecen y conservan. Crítica al devenir político moderno}

En el último capítulo, nos propusimos continuar nuestro análisis de la cuestión de la violencia y la política como términos inescindibles, no con el objeto de insistir en dicha relación, sino orientados a 
vislumbrar los efectos de la misma en la configuración del orden. En este caso, los autores poseen algunos puntos de contacto, si bien debemos reconocer que se caracterizan por contraponerse mutuamente en la mayoría de las discusiones que los atraviesan.

En principio, tanto en Benjamin, en Schmitt y en Arendt, pudimos observar la presencia de una crítica profunda a la modernidad política. Por parte de los primeros, la misma se dirige especialmente al devenir "degenerativo" de la democracia liberal parlamentaria, y al modo de pensar la política desde el liberalismo, particularmente desde la perspectiva schmittiana. Por su parte, Arendt se orienta en una crítica a la teoría política moderna en cuanto la misma ha interpretado mal a los griegos, ha confundido los términos poder y violencia, convirtió a la política en un medio.

Por otro lado, el aporte sustancial de Benjamin y Schmitt al tema de la violencia y la política, lo encontramos en el carácter que se le asigna al orden jurídico y al derecho, ambos aparecen superpuestos con la fuerza y la ley. Podemos decir que términos como autoridad, poder, política, violencia y fuerza de ley aparecen como nociones que refieren a lo mismo. Esto resulta claro en Benjamin, para quien la violencia mítica o fundadora y el derecho se configuran uno con el otro, en una superposición que no permite su distinción. De todas maneras, el autor reconoce una violencia que puede desandar el derecho, es decir, no solo presentarse separada del mismo, sino derribarlo. Esta violencia pura o divina es de carácter exterior al derecho, y justamente por no legitimarse en el mismo es que puede reclamar el derrumbe del Estado y del orden jurídico.

En contraposición, Schmitt buscará neutralizar toda posibilidad de violencia o política que logre extinguir el orden jurídico. Incluso cuando revaloriza el decisionismo político de la dictadura soberana, busca, en todo momento, la reinscripción en un orden. No cancela nunca y por completo al orden jurídico, con precisión apunta a su mera suspensión para poder conservarlo. Como veremos a partir del análisis del estado de excepción, Schmitt reconocerá el conflicto, acepta la suspensión de la norma jurídica y del Estado, acepta la tra- 
gedia del soberano decisionista, pero lo hace siempre en vistas de un orden potencial que confía se constituirá.

En relación al pensamiento de la política, vemos que Benjamin y Arendt se alejan de la tradición filosófica política. Mientras Benjamin critica el orden jurídico que tienden a sesgar y provocar el olvido de la violencia fundadora y apela a destruirlo por fuera del mismo, lo hace sin pretensión alguna de reinscribirlo luego en otro orden diferente. Arendt, al realizar una crítica tan profunda a la filosofía política como aquella forma de pensamiento político de la modernidad, toma distancia de sus categorías conceptuales y de sus marcos analíticos, rechaza la despolitización propiamente moderna.

Del análisis del modo en que Benjamin ha trabajado su crítica a la violencia intentamos extraer el lugar que ocupa la misma en el orden político y los fundamentos que sostiene la crítica en sí. En este sentido, podemos observar que el autor aborda a la violencia a partir del orden jurídico, esto le permite distinguir — cuando se trate de la violencia como medio- dos características esenciales de la violencia (mítica), la que funda el derecho y la que lo conserva. Benjamin tiene la virtud de trascender el mero análisis de la violencia y el derecho, la de fuerza y la ley, ahonda en la superposición de dichos términos de modo de tornarlos indistintos. En base a su carácter indistinguible, toda violencia, incluso la que intente derribar un Estado, que busque legitimarse en el derecho, mantendrá el orden jurídico intacto. A su vez, el orden jurídico (el derecho y la violencia mítica) posee la capacidad de reproducción, de conservación y de producir una consciencia amnésica. Por su parte, la violencia pura (divina) la presenta Benjamin como aquella que logra derribar el orden jurídico, es decir, el derecho. La violencia pura funciona de un modo totalmente externo al derecho, viene a romperlo y se vuelve irreductible a cualquier vínculo exterior, es una violencia sin límites y posee cierta dimensión revolucionaria.

Por su parte, desde un realismo político decisionista, Schmitt refleja como esencia misma de la política la decisión por quién es el amigo y quien el enemigo, en este sentido, la política expone el conflicto que se presenta en la oposición de los individuos conformantes de 
grupos sociales diversos. Al respecto dirá Grüner (2007) que Schmitt construye sobre la base de la justificación jurídica de su decisionismo teórico - según el cual el momento más alto de la práctica política se expresa en las decisiones ad hoc del Estado de excepción-inspirado en un modelo de Estado mayor en situación de guerra. Ahora bien, esta conclusión indefendiblemente reaccionaria tiene no obstante la "virtud" de traer a colación sin mediaciones ni disfraces, la posibilidad misma de una mutua implicación lógica entre lo jurídico-estatal por un lado y la violencia de la dominación por el otro.

A modo de síntesis, quisiéramos destacar de Benjamin y de Schmitt aquellos elementos teóricos o, mejor dicho, perspectivas analíticas, que resultan distintivas. En primer lugar, la crítica a la violencia de Benjamin implica un aporte sustancial en nuestra reflexión sobre la violencia y el orden político. Justamente, este autor nos indica la relación inseparable entre el orden jurídico y la violencia. El derecho y la ley se presentan de un modo superpuesto con la violencia, lo que nos induce a reconocer en términos como fuerza de ley, poder, autoridad, politica, nociones que refiere a lo mismo y no dejan de fundar y conservar el orden. En base a este reconocimiento, cualquier crítica a la violencia que quiera desandar todo el armado jurídico, debe postularse por fuera del derecho. El poder político no es más que la violencia sancionada por el Estado que reclama su utilización exclusiva ya que de la misma depende su propia existencia.

Por último, la apuesta arendtiana apunta al abandono de la reducción de los asuntos públicos al tema del dominio. Como ya hemos argumentado, la crítica de Arendt a la filosofía política moderna la lleva a deconstruir su tradición de discurso, remontándose a sus orígenes en los griegos y su degeneración posterior, en este camino, abandona las categorías propiamente modernas de la política por encontrarlas erróneas y perjudiciales. Si bien, al igual que Benjamin se aproximan a comprender la política en términos impolíticos, o mejor dicho, ambos desestiman el entramado conceptual filosófico político para analizar el Estado, la política, el poder y la violencia, Arendt, por su parte, destierra la posibilidad de instituir poder desde la violencia, mientras que Benjamin concibe una violencia pura - por ente- 
ro diferente a la violencia mítica del derecho-, que tiene el potencial político de revolucionar por fuera el orden jurídico.

\section{Reflexiones finales}

Llegados a este punto, se nos presenta el enorme desafío de esgrimir algunas palabras a modo de conclusión, reflexiones que intenten reflejar los "hallazgos" de nuestra investigación. El desafío, en nuestro caso, es doble. Por un lado, no quisiéramos repetir lo que hemos dicho a lo largo de nuestro escrito. Por otro lado, difícilmente resulte posible afirmar que hemos arribado a nuevos descubrimientos. Como hemos dicho con frecuencia, la relación de imbricación entre la violencia y la política ha sido una preocupación sobre la cual la teoría política moderna ha recaído con una frecuencia casi constante. De todas maneras, consideramos válido destacar que nuestro recorrido nos ha permitido vislumbrar diferentes modalidades de abordaje de la problemática propuesta, las cuales nos han llevado a destacar nociones del orden político que les corresponden a dichos modos. Asimismo, quisiéramos hacer hincapié en el hecho de que si bien reconocemos un conjunto nada desdeñable de tematizaciones de la violencia, nuestro trabajo contribuye, a su vez, a pensar una teoría política de la violencia.

A partir del conjunto de reflexiones que hemos intentado reflejar en esta tesina, concluimos sin dudas que el orden político difícilmente puede resultar inteligible por fuera de una teoría política de la violencia, del reconocimiento de la violencia fundadora del mismo. Es este reconocimiento el que muchas veces parece ausente en la Ciencia Política actual, frecuentemente eclipsada por estudios (neo)institucionalistas. En consecuencia, resulta por demás relevante recurrir a los clásicos y a la teoría de la violencia y la política. 


\section{Referencias bibliográficas}

AGAMBEN, G. Estado de excepción (Homo Sacer II, I). Cuarta edición. Buenos Aires, Adriana Hidalgo Editora, 2010.

ALTHUSSER, L. "La soledad de Maquiavelo". Conferencia pronunciada el 11 de junio de 1977 en la Fondation Nationale des Sciences Politiques de París. Disponible en: http:// www.scribd.com/doc/97580159/Soledad-de-Maquiavelo-Louis-Althusser

ALTHUSSER, L. Maquiavelo y nosotros. Madrid, Ediciones Akal, 2004.

ARENDT, H. La condición humana. Barcelona/ Buenos Aires/ México, Paidós, 1974.

ARENDT, H. Sobre la violencia. Madrid, Alianza Editorial, 2005.

ARENDT, H. Sobre la revolución. Buenos Aires, Alianza Editorial, 2008.

BENJAMIN, W. Estética y política. Primera edición. Buenos Aires, Los Cuarenta, 2009.

CASSIRER, E. El mito del Estado. México, Buenos Aires, Fondo de Cultura Económica, 1947.

DERRIDA, J. Fuerza de ley. El "fundamento místico de la autoridad". Madrid, Editorial Tecnos (Grupo Anaya, S.A.), 2010.

ELIAS, N. El proceso de la civilización. Investigaciones sociogenéticas y psicogenéticas. México, Fondo de Cultura Económica, 2009.

ESPÓSITO, R. Diez pensamientos acerca de la política. Buenos Aires, Fondo de Cultura Económica, 2012.

ESPÓSITO, R. Inmunitas. Protección y negación de la vida. Buenos Aires, Amorrortu editores, 2009.

ESPÓSITO, R. "La perspectiva de lo impolítico”, en: Revista Nombres. Año X, N¹5, octubre 2000. Córdoba, Argentina. [En línea: 16/04/2017] Disponible en: http://www. revistas.unc.edu.ar/index.php/NOMBRES/article/viewFile/2234/1184

FIRENZE, A. "De la natural conflictividad humana. La imposible construcción de la comunidad en Hobbes", en: Eikasia Revista de Filosofía. Julio 2013. [En línea: 13/05/2017] Disponible en: http://revistadefilosofia.com/autfirenze.htm

FORSTER, R. Benjamin: una introducción. 2da. Edición. Buenos Aires, Quadrata, 2012.

FRANZÉ, J. “La política más allá del Estado: ¿una omisión de la violencia?”, en: Revista española de Ciencia Política. ISSN 1575-6548, No 29, 2012. Pp. 67-83. [En línea: 10/12/20163] Disponible en: http://dialnet.unirioja.es/servlet/articulo?codigo $=4002504$ 
GALLEGOS, E. "Violencia, liberación y política: entre Rousseau, Hobbes y Benjamin", en: XVI Congreso Internacional de Filosofía. Asociación filosófica de México, 2011. Pp. 1922-1933.

GRÜNER, E. Las formas de la espada. Miserias de la teoría política de la violencia. Buenos Aires, Colihue, 2007.

HARVEY, D. "El «nuevo" imperialismo: acumulación por desposesión”. Buenos Aires, CLACSO, 2005. [En línea: 12/03/2017] Disponible en:

http://biblioteca.clacso.edu.ar/gsdl/collect/clacso/index/assoc/D8555.dir/harvey.pdf

HILB, C. "Reflexiones entreveradas sobre la democracia y el miedo", en: CHERESKY, I. y POUSADELA, I., Las instituciones en las nuevas democracias: la cuestión republicana. Buenos Aires, Paidós, 2001. Pp. 443-451.

HILB, C. "Violencia y política en la obra de Hannah Arendt", en: Sociología. Año 16, Número 47, 2001.

HOBBES, T. Leviatán. Buenos Aires, Editorial La Página, 2003.

LEFORT, C. Maquiavelo. Lecturas de lo político. Madrid, Editorial Trotta, 2010.

MANENT, P. "Maquiavelo y la fecundidad del mal”, en: MANENT, P. Historia del pensamiento político liberal. Buenos Aires, Emecé, 1990. Pp. 33-53.

MAQUIAVELO, N. El príncipe. Buenos Aires, Editorial Losada, 2003.

MAQUIAVELO, N. Discursos sobre la primera década de Tito Livio. Madrid, Alianza, 1996.

MARX, K. "La llamada acumulación originaria”, en: MARX, K. El capital. Tomo I. México, Siglo Veintiuno Editores, 2009. Pp. 891-954.

MERLEAU-PONTY, M. “Nota sobre Maquiavelo”, en: MERLEAU-PONTY, M. Signos. Barcelona, Editorial Seix Barral, 1964. Pp. 265-279.

POCOCK, J. G. A. El momento Maquiavélico. El pensamiento político florentino y la tradición republicana atlántica. Madrid, Tecnos Editorial, 2002.

RINESI, E. Política y tragedia: Hamlet entre Maquiavelo y Hobbes. Primera edición. Buenos Aires, Colihue, 2003.

ROUSSEAU, J. J. Discurso sobre el origen y los fundamentos de la desigualdad entre los hombres. Buenos Aires, Losada, 2008.

SCHMITT, C. El concepto de lo "político". Teoría del partisano. Notas complementarias al concepto de lo "político". Buenos Aires, Folios Ediciones, 1984.

SCHMITT, C. Teología política. Madrid, Editorial Trotta, 2009. 
SKINNER, Q. Los fundamentos del pensamiento político moderno. El renacimiento. México,Fondo de Cultura Económica, 1993.

SKINNER, Q. Maquiavelo. Madrid, Alianza Editorial, 1984.

TACCETTA, N. Violencia y derecho: Benjamin, Schmitt, Agamben y el estado de excepción. Ponencia presentada en el III Seminario Internacional Políticas de la Memoria: "Recordando a Walter Benjamin. Justicia, historia y verdad. Escrituras de la memoria". Buenos Aires, octubre de 2010. [En línea : 10/11/2016] Disponible en: http://conti. derhuman.jus.gov.ar/2010/10/mesa-35/taccetta_mesa_35.pdf

WOLIN, S. Política y perspectiva. Continuidad y cambio en el pensamiento político occidental. Buenos Aires, Amorrortu Editores, 2001.

ZAVALA HYDE, C. "La polémica entre Benjamin y Schmitt en el Homo Sacer de Agamben”. Universitat Autònoma de Barcelona, 2008. [En línea: 17/11/2016] Disponible en: http://www.ub.edu/demoment/jornadasfp2008/PDFs/16-agamben.pdf 